\title{
Image of the month: Mauriac variant: a rare complication of poorly controlled diabetes
}

\author{
Authors: Amera Elzubeir, ${ }^{A}$ Syed Alam ${ }^{B}$ and James Sington ${ }^{C}$
}

\begin{abstract}
We present a case of Mauriac syndrome in a young woman with poorly controlled type 1 diabetes mellitus. Liver complications are well known in the context of type 2 diabetes mellitus, it is associated metabolic complications and with the non-alcoholic fatty liver disease spectrum. This case brings to light a less well-known liver complication associated with type 1 diabetes mellitus.
\end{abstract}

KEYWORDS: Mauriac syndrome, hepatology, liver, diabetes

DOI: $10.7861 /$ clinmed.2020-0826

\section{Case presentation}

A 46-year-old woman with poorly controlled insulin dependent diabetes mellitus, diagnosed at the age of 30 years old, was referred to the gastroenterology clinic following admission to the emergency department (ED) with abdominal pain and significantly deranged liver function tests (LFTs), warranting further investigation.

Laboratory studies revealed a serum glucose level of $17.1 \mathrm{mmol} / \mathrm{L}$, amylase of $63 \mathrm{U} / \mathrm{L}$, C-reactive protein of $5 \mathrm{mg} / \mathrm{L}$, bilirubin of $18 \mu \mathrm{mol} / \mathrm{L}$, albumin of $30 \mathrm{~g} / \mathrm{L}$, alkaline phosphatase of $483 \mathrm{U} / \mathrm{L}$, alanine aminotransferase of $267 \mathrm{U} / \mathrm{L}$, gamma-glutamyl transferase of $1,314 \mathrm{U} / \mathrm{L}$, international normalised ratio of 0.96 , platelets of 394 $\times 10^{9} / \mathrm{L}$ and cholesterol of $6.0 \mathrm{mmol} / \mathrm{L}$. Her glycated haemoglobin $(\mathrm{HbA1c})$ levels in the year preceding this admission had persistently been in triple digits ranging 102-116 mmol/L, suffering multiple admissions with diabetic ketoacidosis (DKA).

Contrast enhanced computed tomography (CT; Fig 1a) revealed massive hepatomegaly, with a smooth capsule and no focal liver lesions. A non-invasive liver screen was negative for viral, autoimmune or metabolic causes of liver disease. An outpatient liver biopsy was performed following clinic review. Liver histology revealed steatohepatitis, mild fibrosis and diffuse glycogen accumulation (Fig 2).

Authors: A gastroenterology registrar, Norfolk and Norwich University Hospital, Norwich, UK; ${ }^{B}$ hepatology consultant, Norfolk and Norwich University Hospital, Norwich, UK; Chistopathology consultant, The Cotman Centre, Norwich, UK
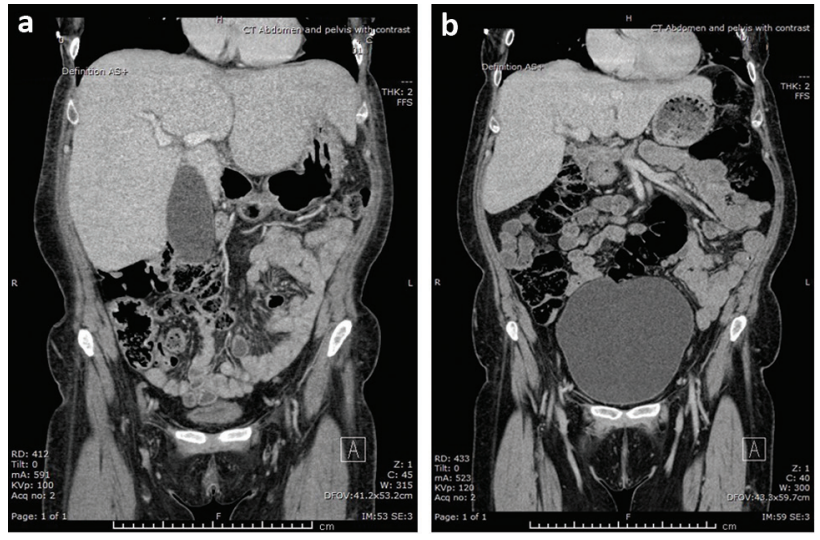

Fig 1. Computed tomography of the abdomen and pelvis (coronal section) a) Marked hepatomegaly showing $22 \mathrm{~cm}$ craniocaudal length. b) Resolution of hepatomegaly with a $6 \mathrm{~cm}$ reduction in liver craniocaudal length.

Following a period of weight loss and significantly improved glycaemic control, her $\mathrm{HbA} 1 \mathrm{c}$ reduced to $71 \mathrm{mmol} / \mathrm{L}$, and her LFTs normalised completely. A repeat $\mathrm{CT}$ (Fig $1 \mathrm{~b}$ ) revealed resolution of the hepatomegaly with a $6 \mathrm{~cm}$ reduction in the craniocaudal length of the right lobe of liver.

\section{Discussion}

Hepatic glycogenesis (HG) is a unique clinical entity, possibly under-diagnosed due to the difficulty in distinguishing it clinically from non-alcoholic fatty liver disease (NAFLD). ${ }^{1} \mathrm{HG}$ is a rare complication of poorly controlled type 1 diabetes mellitus, characterised by glycogen accumulation in hepatocytes. ${ }^{2}$ Mauriac syndrome was first described in 1930 as a glycogenic hepatopathy characterised by hepatomegaly, deranged liver enzymes, cushingoid appearance, hypercholesterolaemia, growth failure and delayed puberty. ${ }^{2}$ Mauriac syndrome is more commonly recognised in children and adolescents, however, there are reports of cases in adults, albeit not always with the characteristic extrahepatic features. ${ }^{3}$ Patients typically present with abdominal pain, mediated by liver capsule stretch due to hepatomegaly. With strict glycaemic control, HG has an excellent prognosis with no reported cases of end-stage liver disease. ${ }^{4}$ Liver biopsy is required to differentiate between NAFLD and HG. 

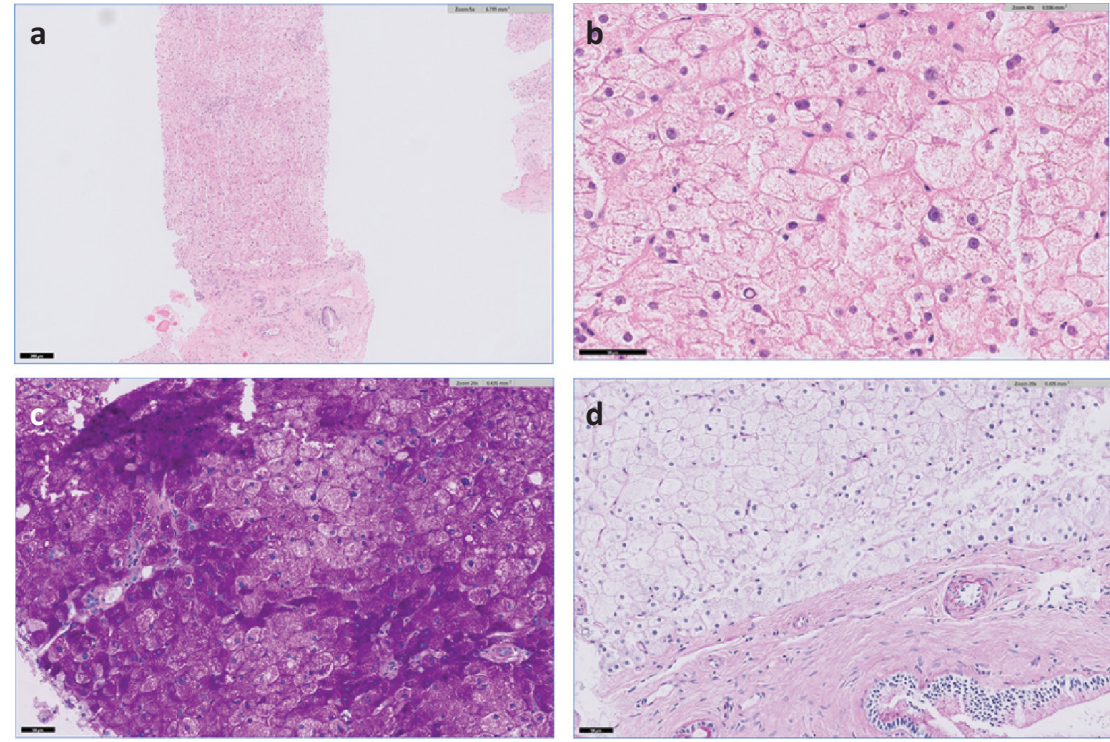

Fig 2. Histopathology imaging. a) Haematoxylin and eosin stain $\times 50$. b) Haematoxylin and eosin stain $\times 200$. c) Periodic acid Schiff stain $\times 100$ showing abundantly glycogenated cytoplasm. d) Diastase-periodic acid Schiff stain $\times 100$ showing glycogenated cytoplasm has disappeared after digestion.

\section{References}

1 Giordano S, Martocchia A, Toussan L et al. Diagnosis of hepatic glycogenosis in poorly controlled type 1 diabetes mellitus. World ] Diabetes 2014;5:882-8.

2 Julián MT, Alonso N, Ojanguren I et al. Hepatic glycogenosis: an underdiagnosed complication of diabetes mellitus? World J Diabetes 2015;6:321-5.

3 Parmar N, Atiq M, Austin L et al. Glycogenic hepatopathy: thinking outside the box. Case Rep Gastroenterol 2015;9:221-6.
4 Patita M, Nunes G, Alves de Matos A, Coelho H, Fonseca C. Mauriac syndrome: a rare hepatic glycogenosis in poorly controlled type 1 diabetes. GE Port J Gastroenterol 2019:26:370-4.

Address for correspondence: Dr Syed Alam, Norfolk and Norwich University Hospital. Colney Lane, Norwich, Norfolk NR4 7UY, UK.

Email: syed.alam@nnuh.nhs.uk

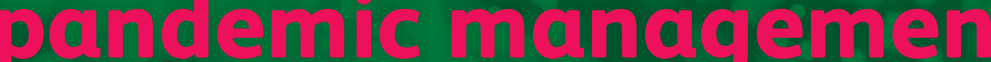

\section{A new Clinical Medicine and Future Healthcare Journal subject collection}

Articles relating to the COVID-19 pandemic are now gathered together in one handy online subject collection for you to browse.

Browse the collection: www.rcpjournals.org/covid-19 


\section{Exceptional \\ cancer homecare. \\ Led by you, \\ delivered by us.}

We're one of the UK's largest providers of private cancer therapies, working closely with clinicians, private medical insurers and patients for over 25 years. Our 150 specialist nurses provide high quality cancer treatments and one-to-one care from the comfort, convenience and safety of patients' homes.

To find out more email cancerservices@hah.co.uk or visit www.hah.co.uk/cancer 